\title{
Risk Factors for Progression to Regular Injection Drug Use among Street-Involved Youth in a Canadian Setting
}

\author{
Kora DeBeck ${ }^{1,2}$, Thomas Kerr ${ }^{1,3}$, Brandon DL Marshall ${ }^{4}$, Annick Simo ${ }^{1}$, Julio Montaner ${ }^{1,3}$, \\ and Evan Wood ${ }^{1,3}$ \\ ${ }^{1}$ British Columbia Centre for Excellence in HIV/AIDS \\ ${ }^{2}$ School of Public Policy, Simon Fraser University \\ ${ }^{3}$ Division of AIDS, Department of Medicine, University of British Columbia \\ ${ }^{4}$ Department of Epidemiology, Public Health Program, Brown University
}

\begin{abstract}
Background-Street-involved youth are at high risk for experimenting with injection drug use; however, little attention has been given to identifying the factors that predict progression to ongoing injecting.
\end{abstract}

Methods-Logistic regression was used to identify factors associated with progression to injecting weekly on a regular basis among a Canadian cohort of street-involved youth.

Results-Among our sample of 405 youth who had initiated injecting at baseline or during study observation, the median age was 22 years (interquartile range $[\mathrm{IQR}]=21-24$ ), and $72 \%$ (293) reported becoming a regular injector at some point after their first injection experience. Of these, the majority $(n=186,63 \%)$ reported doing so within a month of initiating injection drug use. In multivariate analysis, the drug used at the first injection initiation event (opiates vs. cocaine vs. methamphetamine vs. other; all $p>0.05$ ) was not associated with progression; however, younger age at first injection (adjusted odds ratio $[\mathrm{AOR}]=1.13$ ), a history of childhood physical abuse ( $\mathrm{AOR}=1.81$ ), prior regular use of the drug first injected ( $\mathrm{AOR}=1.77)$, and having a sexual partner present at the first injection event $(\mathrm{AOR}=2.65)$ independently predicted progression to regular injecting.

Conclusion-These data highlight how quickly youth progress to become regular injectors after experimentation. Findings indicate that addressing childhood trauma and interventions such as evidence-based youth focused addiction treatment that could prevent or delay regular noninjection drug use, may reduce progression to regular injection drug use among this population.

() 2013 Elsevier Ireland Ltd. All rights reserved.

Send correspondence to: Kora DeBeck, BC Centre for Excellence in HIV/AIDS, 608-1081 Burrard Street, Vancouver, B.C., CANADAV6Z 1Y6, Tel: 604-682-2344 ext:66784, uhri-kd@cfenet.ubc.ca.

Authors Contributions: The specific contributions of each author are as follows: KD and EW designed the study and wrote the protocol, KD managed the literature searches and prepared the first draft of the analysis; AS conducted the statistical analyses with input from KD, EW and BM; all authors contributed to the main content and provided critical comments on the final draft. All authors approved the final manuscript.

Competing Interests: All other authors declare that they have no conflicts of interest.

Publisher's Disclaimer: This is a PDF file of an unedited manuscript that has been accepted for publication. As a service to our customers we are providing this early version of the manuscript. The manuscript will undergo copyediting, typesetting, and review of the resulting proof before it is published in its final citable form. Please note that during the production process errors may be discovered which could affect the content, and all legal disclaimers that apply to the journal pertain. 


\section{Keywords}

injection drug use; injection initiation; street-involved youth; injection prevention; physical abuse

\section{INTRODUCTION}

Injection drug use is a significant public health problem and is associated with a range of adverse health and social outcomes, including blood-borne disease transmission, fatal overdose, and engagement in criminal activity (DeBeck et al., 2007; Marshall et al., 2011; Miller et al., 2009; Werb et al., 2008). Among young people, the use of drugs via injection is of particular concern, since youth have been found to be more likely to share contaminated syringes (Kipke et al., 1996; Lloyd-Smith et al., 2008) and drug injection has been shown to be an independent predictor of mortality among street-involved youth (Roy et al., 1998).

Preventing youth from initiating injection drug use remains a key public health priority; however, little information is available on the frequency of experimentation with injecting and whether this translates into high rates of sustained injection drug use. We undertook this study to assess experimentation with injecting and factors associated with progression to regular injection drug use among a Canadian cohort of drug-using street-involved youth.

\section{METHODS}

Data for this study was obtained from the At-Risk Youth Study (ARYS), an open prospective cohort of street-involved youth who use illegal drugs in Vancouver, Canada. The study methods have been described in detail previously (Wood et al., 2006). In brief, study recruitment involved extensive street-based outreach and snowball sampling of streetinvolved youth. Street-involved was defined as being absolutely, periodically or temporally at risk of being homeless, or using services for vulnerable youth and spending a substantial amount of time on the street or heavily involved in the street economy (Daly, 1998; Marlatt et al., 2011; Marshall et al., 2009). To be eligible, participants at baseline must have been age 14 to 26, reported use of illegal drugs (other than or in addition to marijuana) in the last 30 days, and provided written informed consent. At enrollment and on a biannual basis, participants complete an interviewer-administered questionnaire and provide a blood sample for serologic testing. All participants are compensated with a nominal stipend (\$20 CDN) for their time.

To assess progression to regular injection drug use after injection initiation, the present analysis included participants who reported ever having injected illicit drugs at baseline or at some point during study follow-up (between September 2005 and November 2012), defined as a affirmative response to the question, Have you ever used a needle to chip, fix, or muscle even once? Study participants who were injection naïve at baseline and remained injection naïve throughout the entire study period were excluded from the analysis. Since a number of variables of interest were based on the circumstances of youth's first injection event, data from the first study visit that included a report of injection drug use was used in our analysis to minimize potential recall issues. The primary outcome of interest was progression to becoming a regular injector after the first injection event. Specifically, participants were asked to indicate how much time had passed after the first time they injected before becoming a regular injector, defined as injecting at least once a week on average on a regular basis. Potential response categories included: never, next day to less than one week, more than one week but less than one month, one month to one year, longer than one year. Explanatory variables of interest included the following sociodemographic factors: age at first injection (per year older); gender (female vs. male); and Aboriginal ancestry (self identify as Inuit, Métis, First Nations vs. others). To assess the potential role of drug types, 
we also considered the drug used at the first injection event. The most common drug type used was opiates, so it was defined as the reference category; this approach is consistent with previous studies of street-involved youth in other settings (Steensma et al., 2005). The 'opiate' category included reports of the following drugs used at first injection: heroin; heroin mixed with methamphetamine; heroin mixed with cocaine; Dilaudid (hydromorphone); morphine; and codeine. Other mutually exclusive categories were: 'cocaine', which included reports of cocaine and crack; 'methamphetamine', which included reports of crystal methamphetamine, methamphetamine, and speed; and 'other' which included Talwin (pentazocine), Ritalin (methylphenidate), steroids, adrenaline, alcohol, dimethyltryptamine (DMT), MDMA (ecstasy), ketamine, and phencyclidine (PCP). Other variables of interest included five forms of childhood maltreatment, derived from the Childhood Trauma Questionnaire (CTQ), which has been shown to be valid and reliable among substance-using youths (Bernstein et al., 2003; Fink et al., 1995). The CTQ is a 28item survey that measures the following five forms of maltreatment: physical abuse, sexual abuse, emotional abuse, physical neglect, and emotional neglect. Five subscales on the CTQ survey with predetermined cut-off scores are thus used to define trauma levels for each form of maltreatment. The four levels of trauma are: none (to minimal), low (to moderate), moderate (to severe), and severe (to extreme). As in previous work, we have collapsed the trauma levels into two categories, 'none/low' and 'moderate/severe' (Kerr et al., 2009; Stoltz et al., 2007). Lastly, other factors considered relate to the circumstances of the first injection event and include: prior regular use of drug first injected, defined as at least weekly use of the drug in the month preceding injection initiation (yes vs. no; note: if the first injection event was reported as poly-drug use, regular use of any one of the drugs that was injected was considered prior regular use of drug first injected); duration of illicit hard drug use prior to first injection event, defined as the number of years between the age at injection initiation and the age at first non-injection hard drug use ('hard' drugs defined as heroin, cocaine, crack, or crystal methamphetamine) per additional year; being alone at first injection event (yes vs. no); having a family member present at first injection event, family members included parent(s), sibling, or other family members (yes vs. no); having a sexual partner present at first injection event (yes vs. no); having older people present at first injection event (yes vs. no); and requiring assistance to inject at first injection event (yes vs. no).

Logistic regression was used to determine factors associated with progression to regular injection drug use. In bivariable analysis, categorical explanatory variables were analyzed using Pearson's chi-square test and continuous variables were analyzed using the MannWhitney test. To evaluate factors independently associated with our outcome of interest, all variables with $\mathrm{p}$-values that were $p<0.1$ in bivariable analyses were considered in a multivariate logistic regression. The model selection procedure was done based on the Akaike Information Criterion (AIC) with the best subset selection procedure (Shtatland et al., 2001). All statistical analyses were performed using SAS software version 9.2 (SAS, Cary, NC). All $p$-values are two sided.

\section{RESULTS}

Over our study period, 1029 individuals were enrolled, among whom 405 (39\%) participants experimented with injection drug use, either before study enrollment or over the study follow-up, and completed all items on the CTQ and other measures of interest. Among this sample, $131(32 \%)$ were female, the median age was 22 years (interquartile range [IQR] = $21-24$ ), and the median number of years since their first injection experience was 4.0 (IQR $=1.0-7.0)$. Subsequent to their first injection, $293(72 \%)$ participants progressed to become a regular injector. Among this group, after the first injection experience, $151(51 \%)$ were regular injectors within one week, and a cumulative total of $186(63 \%)$ were regular 
injectors within a month, and 253 (86\%) were regular injectors within a year; only 40 (14\%) of participants took longer than one year to transition to regular injection.

As shown in Table 1, opiates were the most common category of drug used at injection initiation $(49 \%, \mathrm{n}=197)$, followed by methamphetamine $(24 \%, \mathrm{n}=97)$, cocaine $(21 \%, \mathrm{n}=85)$, and other $(6 \%, \mathrm{n}=26)$. Bivariate and multivariate results are also displayed in Table 1 . As shown, factors associated with progression to regular injection drug use in bivariable analysis included age at first injection, female gender, moderate to severe childhood physical abuse, moderate to severe childhood emotional neglect, prior regular use of drug first injected, duration of illicit hard drug use prior to first injection event, and having a sexual partner present at the first injection event (all $p<0.05$; Table 1). Factors found to be independently associated with progression to regular injection drug use in the final multivariable model included: younger age at first injection (adjusted odds ratio [AOR] $=$ $1.13,95 \%$ confidence interval [CI]: $1.05-1.22$ ); a history of childhood physical abuse $(\mathrm{AOR}=1.81,95 \% \mathrm{CI}: 1.07-3.07)$; prior regular use of drug first injected $(\mathrm{AOR}=1.77$, $95 \%$ CI: $1.07-2.93)$ and having a sexual partner present at first injection event (AOR = $2.65,95 \%$ CI: $1.16-6.04)$.

\section{DISCUSSION}

We found that $72 \%$ of street-involved youth who experimented with injecting progressed to regular injection drug use, and the majority transitioned in less than one week. Although the type of drug first used to inject was not associated with progression, younger age at first injection, prior regular use of the drug first injected, a history of childhood physical abuse, and having a sexual partner present at injection initiation all significantly increased the odds of becoming a regular injector.

The frequency and speed with which youth in our study transitioned to regular injection drug use is alarming and confirms the importance of early interventions for at-risk youth (Novelli et al., 2005; Roy et al., 2007; Vlahov et al., 2004). Delaying injection initiation also appears to have a protective influence on whether youth become a regular injector. This highlights a potential role for secondary prevention efforts for youth who have already initiated hard drug use but have not progressed to injection. Recent studies among streetinvolved youth suggest that structural factors, such as a lack of housing, play a role in facilitating injection initiation among youth who use illicit hard street drugs (Feng et al., 2013). Our findings suggest that if interventions such as housing are able to prevent or even delay injection initiation, this could have a significant impact on preventing regular injection drug use among vulnerable youth.

The association between childhood physical abuse and drug injecting has been reported elsewhere (Fergusson et al., 2008). A prior study in our setting found that childhood physical abuse was the only form of childhood maltreatment independently associated with prevalent injection drug use (Kerr et al., 2009). Building on this previous finding, the current study indicates that physical abuse is not only associated with experimenting with risky drug use practices, but is also an independent predictor of becoming a regular injection drug user.

Although specific drug types have previously been associated with injection initiation (Wood et al., 2008), our analysis suggests that the properties and characteristics of a particular drug do not appear to be associated with transitions to sustained injection drug use. While drug use patterns, such as prior frequent use of the drug first injected and younger age at injection initiation, predicted subsequent regular injection, no single drug type resulted in more problematic drug use patterns. Rather, our analysis indicates that in addition to drug use patterns, social factors, such as having a sexual partner present at the first injection, and early life factors, such as particular forms of childhood trauma, appear to 
be salient factors in transitioning to regular injection drug use. These findings are supported by a growing body of literature indicating that distal familial, social and structural factors are key determinants of high risk drug use (Fergusson et al., 2008; Hadland et al., 2012; Kerr et al., 2009; Ompad et al., 2005; Westermeyer et al., 2001; Wu et al., 2010). This has implications for current drug use prevention efforts as it underscores the importance of early interventions, including the provision of early childhood support for children who experience abuse (Toumbourou et al., 2007). In addition, our study highlights the pressing need to expand evidence-based addiction treatment and other secondary prevention efforts, and suggests that greater attention should be given to developing innovative addiction treatments for youth that can alter drug use trajectories.

This study has a number of limitations. First, ARYS is not a random sample and therefore our findings may not generalize well to other populations of drug-using street-involved youth. Secondly, since our study included participants who had recently initiated injection drug use and thus may not have had sufficient observed time to progress to become a regular injector, our findings may underestimate the true prevalence of progression to regular injection drug use among novice street-involved injectors. Among participants who did not report progressing to become regular injectors, the median number of years at the time of interview since injection initiation was 2.9 (IQR $=1.3-5.8$ ); among regular injectors the median number of years was 4.0 (IQR 1.0 - 7.0). Despite these differences, given that $86 \%$ of regular injectors report having transitioned to regular injection within a year, we expect the effect of this potential misclassification to be relatively minor. Thirdly, our measures relied on self-report, which is vulnerable to response bias. Finally, an ideal sample would have been to follow injection naïve youth forward to assess for subsequent injecting patterns. Unfortunately, we do not currently have adequate follow-up post injection initiation among youth who initiated injecting during the study period to allow for this type of analysis with the ARYS cohort.

In sum, our study found that a high proportion of street-involved youth experimenting with drug injecting progressed to become regular injectors in a relatively short period of time. While specific drugs used at the time of first injection were not predictive of subsequent regular use, drug use patterns, specifically prior regular use of the drug first injected and younger age at first injection, as well as having a history of childhood physical abuse and having a sexual partner present at the first injection event were. These data highlight the importance of expanding evidence-based primary and secondary drug use prevention and treatment options for youth, and imply that efforts to support children who experience abuse may be more important than focusing on specific illicit substances.

\section{Acknowledgments}

Role of Funding Sources: The study was supported by the US National Institutes of Health (R01-DA028532) and the Canadian Institutes of Health Research (MOP-102742). This research was undertaken, in part, thanks to funding from the Canada Research Chairs program through a Tier 1 Canada Research Chair in Inner City Medicine, which supports Dr. Evan Wood. Dr. Kora DeBeck is supported by a MSFHR/St. Paul's Hospital - Providence Health Care Career Scholar Award. Dr. Julio Montaner has received an Avant-Garde award (DP1DA026182) from the National Institute of Drug Abuse, US National Institutes of Health. Funding sources had no further role in study design; in the collection, analysis and interpretation of data; in the writing of the report; or in the decision to submit the paper for publication.

The authors thank the ARYS study participants for their contribution to the research, as well as current and past researchers and staff. We would specifically like to thank CodyCallon, Jennifer Matthews, Deborah Graham, Peter Vann, Steve Kain, Tricia Collingham, and CarmenRock for their research and administrative assistance. 


\section{References}

Bernstein DP, Stein JA, Newcomb MD, Walker E, Pogge D, Ahluvalia T, Stokes J, Handelsman L, Medrano M, Desmond D, Zule W. Development and validation of a brief screening version of the Childhood Trauma Questionnaire. Child Abuse Negl. 2003; 27:169-190. [PubMed: 12615092]

Daly G. Homeless. Policies, strategies, and lives on the street. Capital Class. 1998; 22:167-169.

DeBeck K, Shannon K, Wood E, Li K, Montaner J, Kerr T. Income generating activities of people who inject drugs. Drug Alcohol Depend. 2007; 91:50. [PubMed: 17561355]

Feng C, DeBeck K, Kerr T, Mathias S, Montaner J, Wood E. Homelessness independently predicts injection drug use initiation among street-involved youth in a Canadian setting. J Adolesc Health. 2013; 52:499-501. [PubMed: 23299006]

Fergusson DM, Boden JM, Horwood LJ. The developmental antecedents of illicit drug use: evidence from a 25-year longitudinal study. Drug Alcohol Depend. 2008; 96:165-177. [PubMed: 18423900]

Fink LA, Bernstein D, Handelsman L, Foote J, Lovejoy M. Initial reliability and validity of the childhood trauma interview: a new multidimensional measure of childhood interpersonal trauma. Am J Psychiatry. 1995; 152:1329-1335. [PubMed: 7653689]

Hadland SE, Werb D, Kerr T, Fu E, Wang H, Montaner JS, Wood E. Childhood sexual abuse and risk for initiating injection drug use: a prospective cohort study. Prev Med. 2012; 55:500-504. [PubMed: 22954518]

Kerr T, Stoltz JA, Marshall BD, Lai C, Strathdee SA, Wood E. Childhood trauma and injection drug use among high-risk youth. J Adolesc Health. 2009; 45:300-302. [PubMed: 19699428]

Kipke MD, Unger JB, Palmer RF, Edgington R. Drug use, needle sharing, and HIV risk among injection drug-using street youth. Subst Use Misuse. 1996; 31:1167-1187. [PubMed: 8853236]

Lloyd-Smith E, Kerr T, Zhang R, Montaner JSG, Wood E. High prevalence of syringe sharing among street involved youth. Addict Res Theory. 2008; 16:353-358.

Marlatt, GA.; Larimer, ME.; Witkiewitz, K. Harm Reduction: Pragmatic Strategies for Managing High-risk Behaviors. Guilford Press; New York: 2011.

Marshall BD, Kerr T, Shoveller JA, Patterson TL, Buxton JA, Wood E. Homelessness and unstable housing associated with an increased risk of HIV and STI transmission among street-involved youth. Health Place. 2009; 3:753-60. [PubMed: 19201642]

Marshall BD, Milloy MJ, Wood E, Montaner JS, Kerr T. Reduction in overdose mortality after the opening of North America's first medically supervised safer injecting facility: a retrospective population-based study. Lancet. 2011; 377:1429-1437. [PubMed: 21497898]

Miller CL, Kerr T, Fischer B, Zhang R, Wood E. Methamphetamine injection independently predicts hepatitis C infection among street-involved youth in a Canadian setting. J Adolesc Health. 2009; 44:302-304. [PubMed: 19237118]

Novelli LA, Sherman SG, Havens JR, Strathdee SA, Sapun M. Circumstances surrounding the first injection experience and their association with future syringe sharing behaviors in young urban injection drug users. Drug Alcohol Depend. 2005; 77:303-309. [PubMed: 15734230]

Ompad DC, Ikeda RM, Shah N, Fuller CM, Bailey S, Morse E, Kerndt P, Maslow C, Wu Y, Vlahov D, Garfein R, Strathdee SA. Childhood sexual abuse and age at initiation of injection drug use. Am J Public Health. 2005; 95:703-709. [PubMed: 15798133]

Roy E, Boivin JF, Haley N, Lemire N. Mortality among street youth. Lancet. 1998; 352:32. [PubMed: 9800745]

Roy E, Boudreau JF, Leclerc P, Boivin JF, Godin G. Trends in injection drug use behaviors over 10 years among street youth. Drug Alcohol Depend. 2007; 89:170-175. [PubMed: 17258871]

Shtatland, ES.; Cain, E.; Barton, MB. The Perils of Stepwise Logistic Regression and How to Escape Them Using Information Criteria and the Output Delivery System. SUGI 2001 proceedings, paper $222 ; 2001$.

Steensma C, Boivin JF, Blais L, Roy E. Cessation of injecting drug use among street-based youth. J Urban Health. 2005; 82:622-637. [PubMed: 16195471]

Stoltz JA, Shannon K, Kerr T, Zhang R, Montaner JS, Wood E. Associations between childhood maltreatment and sex work in a cohort of drug-using youth. Soc Sci Med. 2007; 65:1214-1221. [PubMed: 17576029] 
Toumbourou JW, Stockwell T, Neighbors C, Marlatt GA, Sturge J, Rehm J. Interventions to reduce harm associated with adolescent substance use. Lancet. 2007; 369:1391-1401. [PubMed: 17448826]

Vlahov D, Fuller CM, Ompad DC, Galea S, Des Jarlais DC. Updating the infection risk reduction Hierarchy: preventing transition into injection. J Urban Health. 2004; 81:14-19. [PubMed: 15047779]

Werb D, Kerr T, Li K, Montaner J, Wood E. Risks surrounding drug trade involvement among streetinvolved youth. Am J Drug Alcohol Abuse. 2008; 34:810-820. [PubMed: 19016187]

Westermeyer J, Wahmanholm K, Thuras P. Effects of childhood physical abuse on course and severity of substance abuse. Am J Addict. 2001; 10:101-110. [PubMed: 11444153]

Wood E, Stoltz JA, Montaner JS, Kerr T. Evaluating methamphetamine use and risks of injection initiation among street youth: the ARYS study. Harm Reduct J. 2006; 3:18. [PubMed: 16723029]

Wood E, Stoltz JA, Zhang R, Strathdee SA, Montaner JS, Kerr T. Circumstances of first crystal methamphetamine use and initiation of injection drug use among high-risk youth. Drug Alcohol Rev. 2008; 27:270-276. [PubMed: 18368608]

Wu NS, Schairer LC, Dellor E, Grella C. Childhood trauma and health outcomes in adults with comorbid substance abuse and mental health disorders. Addict Behav. 2010; 35:68-71. [PubMed: 19775820] 


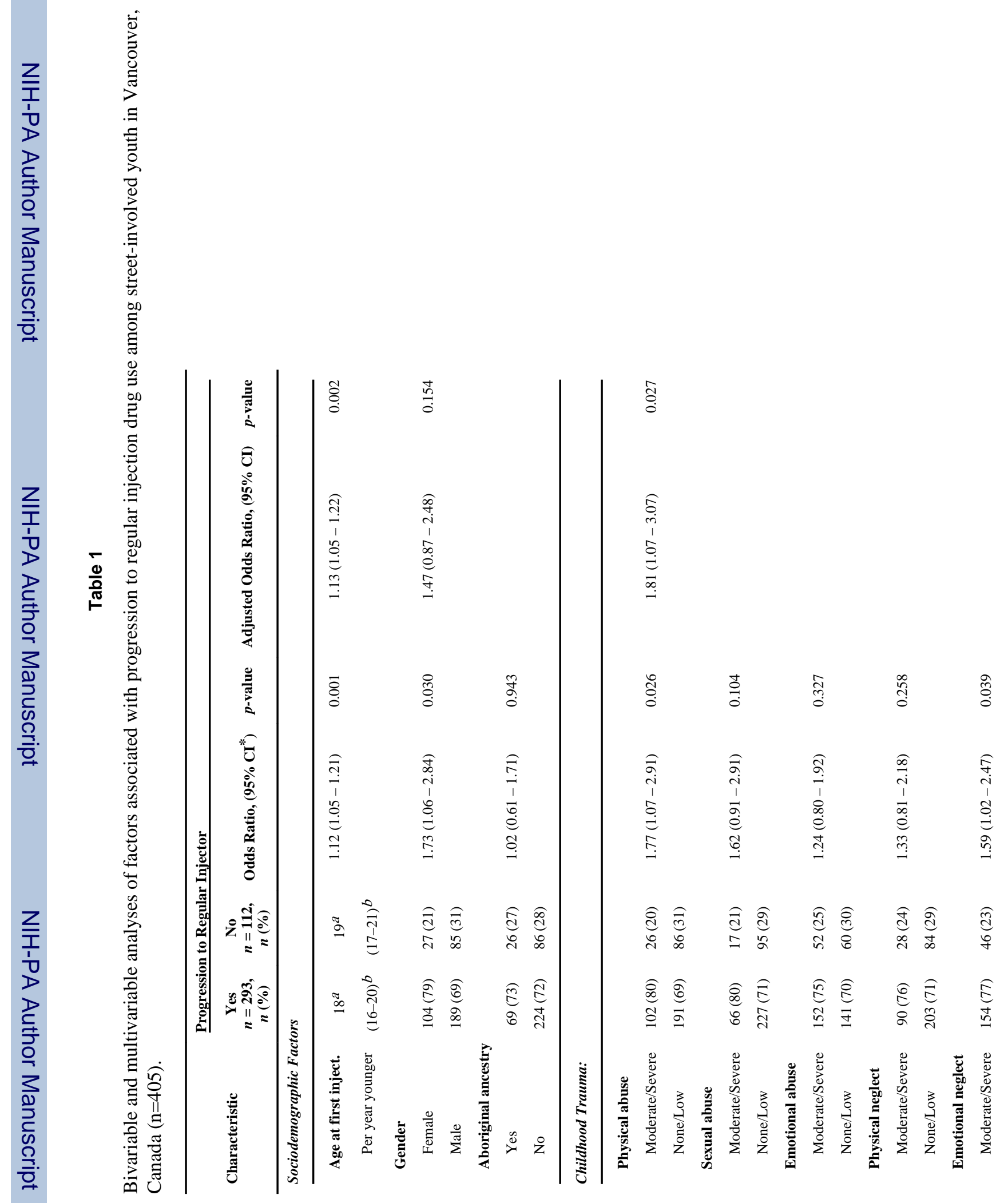




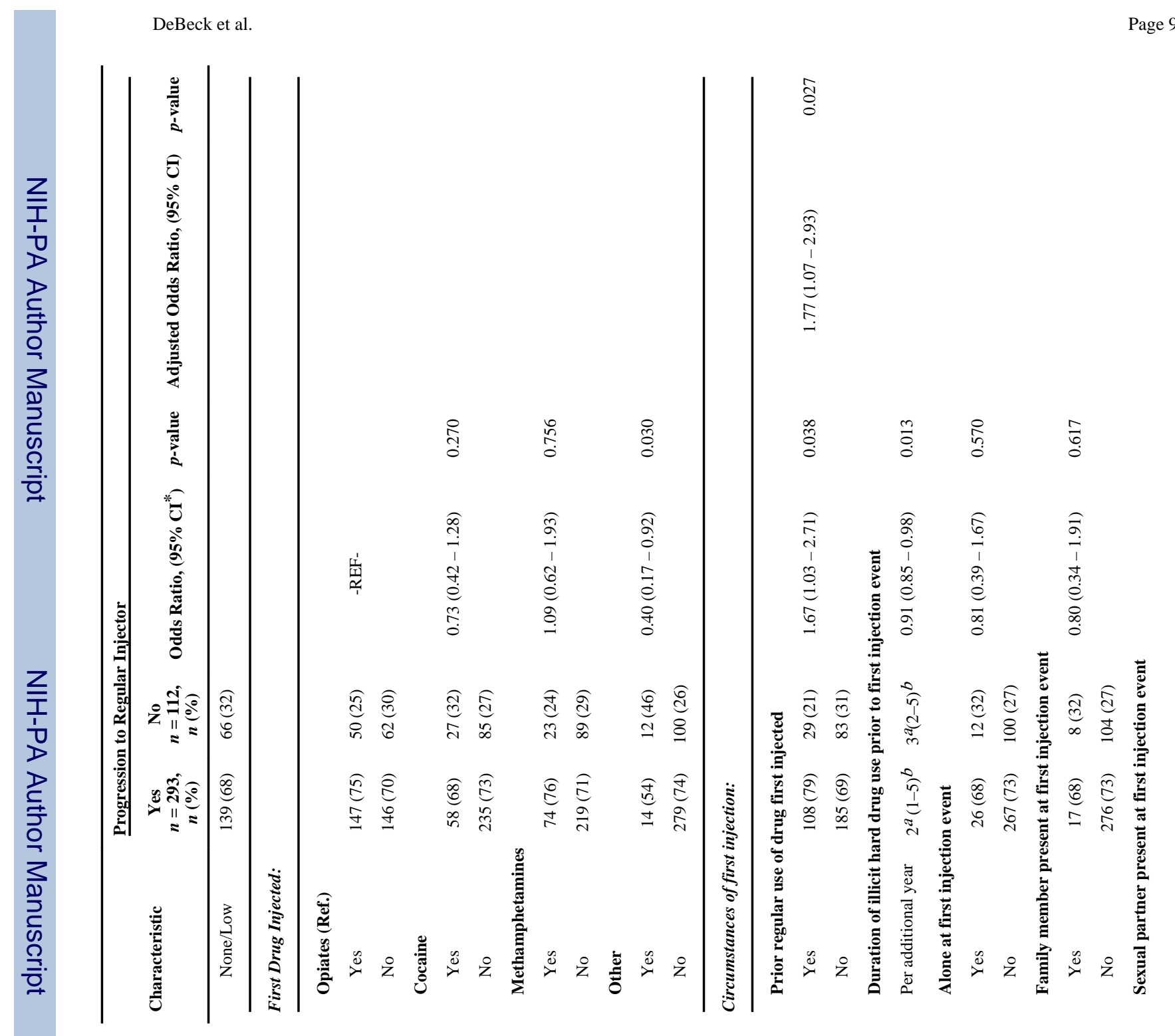

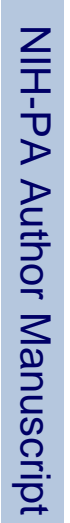




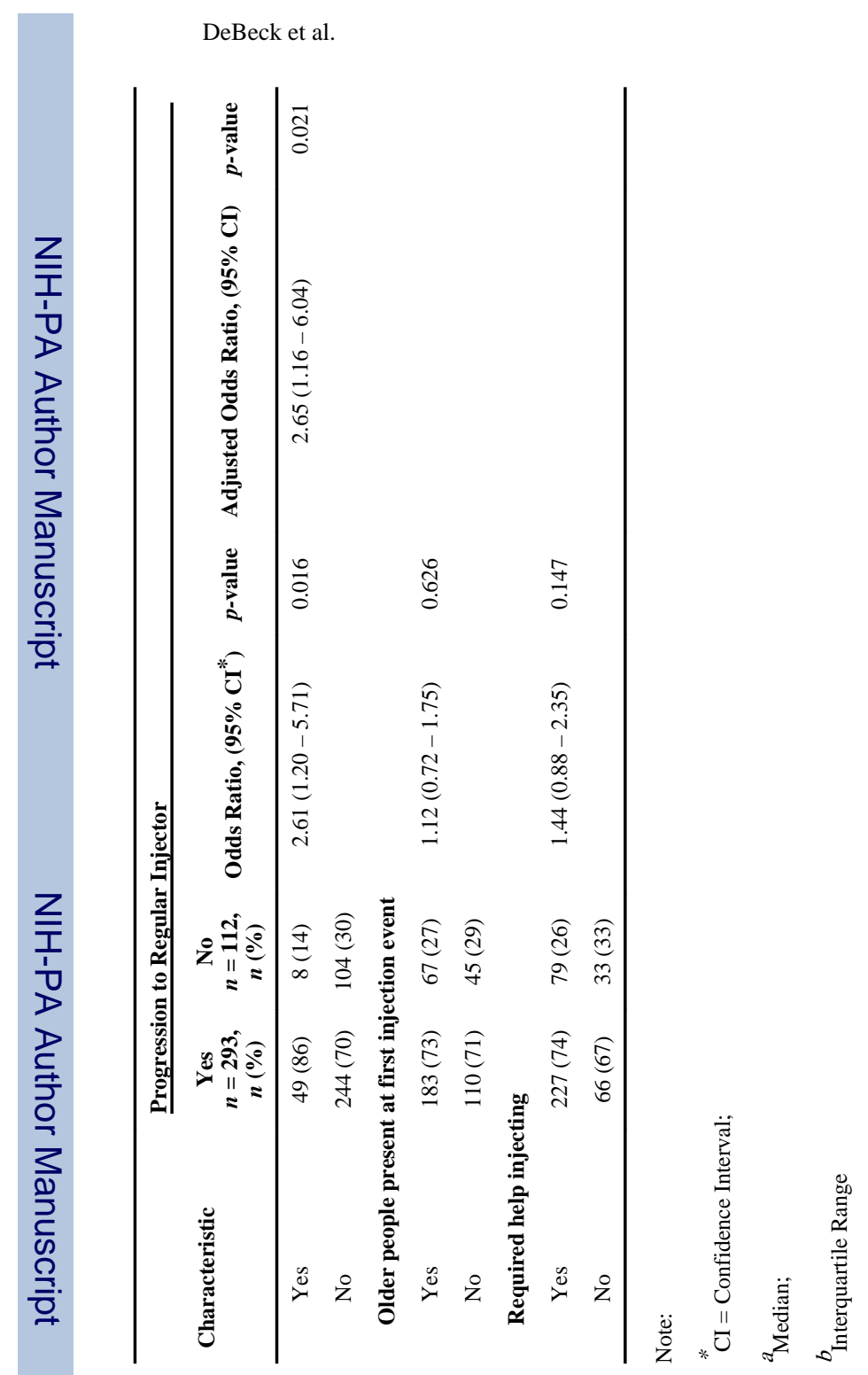

Page 10

Drug Alcohol Depend. Author manuscript; available in PMC 2014 December 01. 